\title{
Studies on Friction Stir Welding of Polymers- A Review
}

\author{
Harish Kumar \\ Department of Mechanical Engineering \\ Brindavan College of Engineering \\ Bangalore, India
}

\author{
S.V. Satish \\ Department of Mechanical Engineering \\ PESIT \\ Bangalore, India
}

\begin{abstract}
Friction Stir Welding (FSW) is a Solid state joining process suitable for producing joints, especially in low dense materials, which are very important due to the reduction in weight. A relatively new technique that appears as a promisingly ecological weld method that enables to less material waste, less energy required and avoid harmful radiations usually associated with the fusion welding technique. FSW technique also developed for joining of polymer materials, which exhibits considerable improvement in strength.

The main focus of this article is on welding thermoplastic polymer materials using FSW technique. This review displays the explanations to reach a well understanding of joining of thermoplastic polymer material using FSW technique is presented.
\end{abstract}

Keywords-Friction Stir Welding; Polymers; process parameters

\begin{abstract}
I. FRICTION STIR WELDING
Friction Stir Welding (FSW) was invented at The Welding Institute (TWI) of UK in 1991[1, 2]. It has found many applications in a wide variety of industries, including aerospace, automotive, and railway. The FSW process takes place in the solid- phase, at temperatures below the melting point of the material, and as a result does not experience problems related to formation of porosity, and cracks. Friction stir welding is a relatively new technique that appears as promisingly ecological weld method that enables to diminish material waste, and to avoid radiations usually associated with the fusion welding techniques $[3,4]$. The lower temperature of the process enables joining with lower distortion and lower residual stresses. FSW has become an attractive joining process as it not requires filler material, shielding gas and the process lacks the fumes, spatter, and arc flash.
\end{abstract}

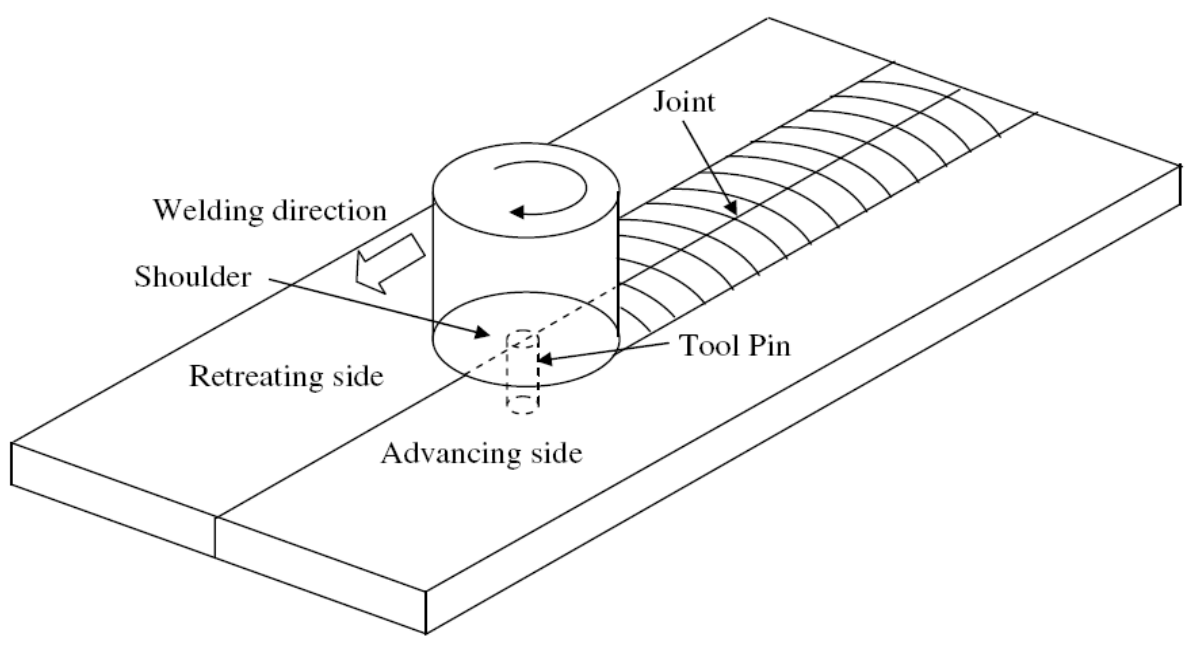

Fig.1.The basic principles of Friction Stir Welding

The Friction Stir Welding machine consists of a rotating tool, which in turn consists of a probe and shoulder. The rotating tool is slowly plunged into the joint line between two pieces of plate material, which are butted together. Frictional heat is generated between the wear resistant tool and the material of the work piece [5]. The frictional heat traverses the joint line and causes joining of two sheets [6]. The process was suitable for joining the plates and sheets; however, it can be employed for pipes and the hollow sections [7].
As in fusion welding, FSW joints have a region that is affected by heat only, known as the heat affected zone (HAZ). The region outside of this, which is unaffected by heat or deformation is the parent material. The region that is affected by both heat and plastic deformation is known as the thermo-mechanically affected zone (TMAZ).

FSW method is most commonly used for square butt joint and lap joint. Another advantage of FSW is that typically little joint preparation is required. 
Tool design is one of the most important factors to consider when designing a FSW joining process. The tool must perform many functions, including generating heat, promoting mixing, breaking up the joint line, creating forging pressure, and preventing the formation of defect. The different designs of tool are flat, featureless shoulders and cylindrical, threaded.

\section{POLYMERS}

A polymer is simply a material composed of many repeated units called monomers that link together into chains or branches. Polymers are created by the process of polymerization wherein, their constituents element called monomers, are reacted together to form polymer chains i.e. 3-dimensional networks forming the polymer bonds. Some polymers like starch, cellulose and rubber occur naturally while others like polyester, nylon and plastic are synthetic. Polymers are categories into two types thermoplastics, and thermosetting polymers.

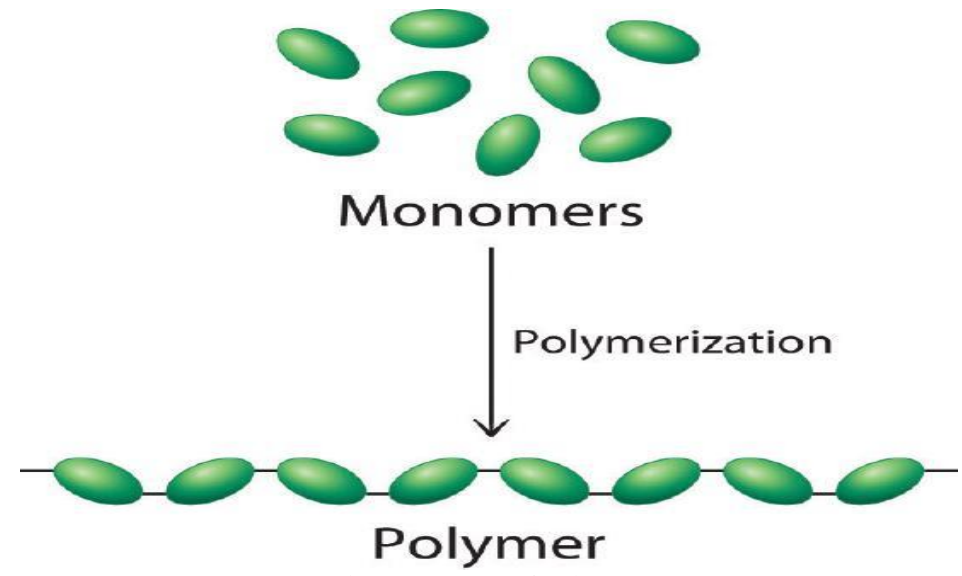

Fig.2. Structure of Polymers

Thermoplastic polymers form when repeating units called monomers link into chains or branches. Thermoplastic polymers readily soften when heated, allowing manufacturers to mold them into a wide range of shapes, then re-soften them and mold them again. This ability to reuse thermoplastic polymers indefinitely means they are highly recyclable. Thermoplastics flow in manner of a fluid state if it heated up the glass transition for amorphous thermoplastics, and flow will occur by heating above the melting temperature in semi-crystalline thermoplastics polymers [8].

Other benefits of these polymers include excellent strength and a tendency to resist shrinking. On the other hand, thermoplastic polymers do have a few drawbacks, including high production costs and the fact they melt easily, which make them inappropriate for some high temperature applications.

The popular examples of thermoplastic polymer are polyethylene, polypropylene, polystyrene, and poly vinyl chloride.

A thermosetting polymer is also known as a thermo-set or thermosetting plastic is a polymer consisting of cross-linked structure or heavily branched molecules. These polymers are in the soft solid or viscous state, on heating undergo extensive cross-linking in moulds and become irreversibly hard as well as insoluble product. The common examples to thermosetting polymers are the epoxy resin, polyester resin, Polyurethanes.

A. Characteristics of Polymers

Most of the polymers are lighter in weight. The various characteristics of polymeric materials are as follows.

1. Low density 2. Good corrosion resistance 3. Good molding ability 4.Excellent surface finish 5.Economical 6 .
Low coefficient of friction 7.Poor mechanical properties 8.Poor temperature resistance 9.Thermal and electrical insulators

\section{POLYMER JOINING}

Friction Stir Welding (FSW) was initially developed for joining Al-alloys [9-10], it also has a great potential for the welding of copper [11], titanium [12], steel [13], magnesium [14], metal matrix composites [15], and different material combinations [16].

However the FSW process was also performed to join polymer materials. It is very important in automotive industry to manufacture lighter, safer, more environmentally friendly and cheaper vehicle. Reduction in vehicle weight can be obtained by replacing steel and cast iron with lightweight materials such as reinforced polymer composites.

A wide range of polymers welded have been successfully welded by FSW, the common polymers welded are polyethylene (PE) [17], polypropylene (PP) [18], polycarbonate (PC) [19], polyamide (PA) [20], and Polymethyl methacrylate (PMMA) [21]. Nanocomposites are also welded by FSW.

Among three kinds of polymeric materials; thermoplastics, thermosets, and elastomers, only thermoplastics are the weldable polymers. It is due to their ability to be reshaped after heating below their degradation temperature. Examples of such polymeric materials include polyvinyl chloride (PVC), Polystyrene (PS), Acrylonitrile Butadiene Styrene (ABS), Polymethyl methacrylate (PMMA), low-density and high-density polyethylene (PE). Others are Polypropylene (PP), Poly tetra fluoro ethylene (PTFE), nylon-6 etc. 
Rotational speed is the major process parameter in FSW process, which varies for each kind of material depending on their physical properties. A higher rotational speed results in the degradation of the polymer, whereas lower rotational speed gives poor mixing thus producing voids in stir zone. Therefore, the need to investigate the optimum parameters for each polymer is vital.

Thermoplastic materials such as polyethylene are used in an expanding range of engineering applications due to their stronger joints, flexibility, resistant to abrasion and to chemicals. Polyethylene has good insulation properties and is easy to weld.

\section{CONCLUSIONS}

Friction Stir Welding (FSW) technique is suitable for joining many polymers. The strength of the welded joint is mainly depends on the pin profile, as different pin profile are used during joining process. For example, the conical pin is reported as best profile for Acrylonitrile butadiene styrene and high-density polyethylene, whereas the threaded cylindrical pin profile is considered most suitable for polypropylene friction stir welding. Also rotational speed is the major process parameter in FSW process. A higher rotational speed results in the degradation of the polymer, whereas lower rotational speed produces voids in stir zone. Compared to traditional fusion welding, FSW exhibits a considerable improvement in strength (close to the strength of the base material), ductility and fatigue properties.

\section{REFERENCES}

[1] W. M. Thomas, E. D. Nicholas, and J. C. Needham, "Friction stir welding “, International patent PCT/GB92102203 and Great Britain patent $9125978.8,1991$.

[2] R. S. Mishra and Z. Y. Ma, "Friction stir welding and processing", Materials science and Engineering, vol. 50, no. 1-2, pp. 1-78, 2005.

[3] Rodrigues DM, Loureiro A, Leitao C, Leal RM, Chaparron BM, Vilaca P. Influence of friction Stir Welding parameters on the microstructural and mechanical properties of friction AA 6016T4 thin welds. Master Des 2009; 30: 1913-21

[4] Feng AH, Xiao BL, Ma ZY. Grain boundary misorientation and texture development in friction stir welded $\mathrm{SiC} / \mathrm{Al}-\mathrm{Cu}-\mathrm{Mg}$ composite. Master Sci Eng A 2008; 497: 515-8.

[5] Mishra RS, De PS, Kumar N. Friction stir welding and processing: science and engineering. Springer International; 2014.

[6] Su JQ, Nelson TW, Mishra RS, Mahoney M. Microstructural investigation of friction stir welded 7050-T651 aluminium. Acta Mater 2003;51: 713-29

[7] Ghosh M, Kumar K, Kailas SV, Ray AK. Optimization of friction stir welding parameters for dissimilar aluminum alloys. Master Des 2010; 31: 3033-7.

[8] P. Ajean-Pierre H. Sautereau, J. Verdu \& R. J. J. Williams, Thermosetting Polymers, Marcel Dekker Inc. (20020

[9] Colligan K. Materials flow behaviour during friction stir welding of aluminum. Weld Res Suppl 1999; 78(7):229-37.

[10] Murr LE, Liu G, McClure JC. Dynamic recrystallization in friction stir welding of aluminum alloy 1100. J Mater Sci Lett 1997; 16: 1801-3

[11] Barlas Z, Uzun H. Microstructure and mechanical properties of friction stir butt welded dissimilar pure copper/brass alloy plates. Int J Mat R (Zeitschrift fur METALLKUNDE) 2010; 101(6):8017

[12] Ramirez AJ, Juhas MC. Microstructural evolution in Ti-6Al-4V friction stir welds. Mater Sci Forum 2003(426-432): 2999-3004.

[13] Sato YS, Nelson TW, Sterling CJ, Steel RJ, Pettersson CO. Microstructure and mechanical properties of friction stir welded SAF 2507 super duplex stainless steel. Mater Sci Eng A 2005; 397 (1-2): $376-84$
[14] Commin L, Dumont M, Masse JE, Barrallier L. Friction stir welding of AZ31 Magnesium alloy rolled sheets: influence of processing parameters. Acta Mater 2009; 57(2):326-34.

[15] Nami H, Adgi H, Sharifitabar M, Shamabadi H. Microstructure and mechanical propertis of friction stir welded $\mathrm{Al} / \mathrm{Mg} 2 \mathrm{Si}$ metal matrix cast composite. Mater Des 2011; 32: 976-83.

[16] Yan Y, Zhang DT, Qiu C, Zhang W. Dissimilar friction stir welding between 5052 aluminium alloy and AZ31 magnesium alloy. Trans Nonf Met Soc China 2010; 20(2): 619-23.

[17] Y. Bozkurt, "The optimization of friction stir welding process parameters to achieve maximum tensile strength in polyethylene sheets", Materials \& design, Vol. 35, (2012), pp 440-445

[18] M. K. Bilici, "Application of Taguchi approach to optimize friction stir spot welding parameters of polypropylene", Material \& design, Vol. 35, (2012), pp 113-119

[19] F. Lambiase, A.Paoletti \& A. Dillio, "Effect of tool geometry onloads developing in friction stir spot welds of polycarbonate sheets", The International journal of advanced manufacturing technology, Vol. 87, Issue 5-8, (2016), pp 2293-2303

[20] J. Goncalves, J.F. dos santos, L.B. Canto \& S.T. Amancio Filho, "Friction spot welding of carbon fiber-reinforced polyamide 66 laminate", Materials letters, Vol. 159, (2015), pp 506-509

[21] S. Hoseinpour, D. T. Azdast, S.R. Ahmadi \& A. Bagheri,"Friction stir spot welding of dissimilar polymethyl methacrylate and acrylonitrile butadiene styrene sheets", Materials \& design, Vol. 45, (2013), pp 135-141 